\title{
"Viral déjà vu" elicits organ-specific immune disease independent of reactivity to self
}

\author{
Doron Merkler, ${ }^{1}$ Edit Horvath, ${ }^{2}$ Wolfgang Bruck, ${ }^{1}$ Rolf M. Zinkernagel, ${ }^{2}$ \\ Juan Carlos de la Torre, ${ }^{3}$ and Daniel D. Pinschewer ${ }^{2}$
}

1Department of Neuropathology, Georg-August-Universität, Goettingen, Germany. ${ }^{2}$ Institute of Experimental Immunology, Department of Pathology, University Hospital of Zürich, Zurich, Switzerland. ${ }^{3}$ Molecular Integrative Neuroscience Department (MIND), The Scripps Research Institute, La Jolla, California, USA.

\begin{abstract}
Autoimmune diseases are often precipitated by viral infections. Yet our current understanding fails to explain how viruses trigger organ-specific autoimmunity despite thymic tolerance extending to many nonlymphohematopoietic self antigens. Additionally, a key epidemiological finding needs to be explained: In genetically susceptible individuals, early childhood infections seem to predispose them to multiple sclerosis (MS) or type 1 diabetes years or even decades before clinical onset. In the present work, we show that the innate immune system of neonatal mice was sufficient to eliminate an attenuated lymphocytic choriomeningitis virus (LCMV) from most tissues except for the CNS, where the virus persisted in neurons (predisposing virus). Virus-specific cytotoxic T cells (CTLs) were neither deleted nor sufficiently primed to cause disease, but they were efficiently triggered in adulthood upon WT LCMV infection (precipitating virus). This defined sequence of viral infections caused severe CNS inflammation that was histomorphologically reminiscent of rasmussen encephalitis, a fatal human autoimmune disease. Yet disease in mice was mediated by antiviral CTLs targeting an epitope shared by the precipitating virus and the predisposing virus persisting in neurons (déjà vu). Thus the concept of "viral déjà vu" demonstrates how 2 related but independently encountered viral infections can cause organspecific immune disease without molecular mimicry of self and without breaking self tolerance.
\end{abstract}

\section{Introduction}

The infectious hypothesis for MS dates back to the nineteenth century (1). Since then, it has been supported by a large number of epidemiological observations (2), of which only few can be mentioned here: Latitude-associated differences in prevalence (2) and relatively low concordance rates between homozygotic twins (3) demonstrate a strong impact of environmental factors besides an undisputed role of the genetic context (4). According to migration studies, environmental conditioning encountered before the age of 15 confers predisposition to disease (2). Yet onset of disease occurs commonly only after years or even decades and often simultaneously with viral infections $(5,6)$. A number of parallel observations including twin discordance rates (7) have been made for type 1 diabetes (T1D). Congenital rubella is a classic though rare example of virus-induced diabetes in humans (8). Moreover, a role for infectious agents has long been suggested by the presence of coxsackie virus-specific serum antibodies in prediabetic and new-onset T1D patients $(9,10)$. This was later supported by the observation that a coxsackie virus isolated from a diabetic patient's pancreas transferred the disease to animals (11). More recently, the findings of seasonality of birth in certain high-prevalence cohorts (12) and elevated enterovirus-specific antibodies in pregnant mothers of children that subsequently develop T1D $(10,13)$ suggest that, similar to MS, environmental factors in fetal or early neonatal life confer genetically susceptible indi-

Nonstandard abbreviations used: ARM, LCMVwt strain Armstrong; GP, glycoprotein; i.c., intracerebral(ly); INDG, GP of VSV serotype Indiana; LCMV, lymphocytic choriomeningitis virus; NP, nucleoprotein; NP396, immunodominant $\mathrm{H}_{-} 2 \mathrm{D}^{\mathrm{b}}$ restricted, LCMV-NP-derived CTL epitope; r-, recombinant; RE, rasmussen encephalitis; rLCMV/INDG, rLCMV expressing INDG instead of LCMV-GP; rVSV/LCMV-GP, rVSV expressing LCMV-GP instead of INDG; T1D, type 1 diabetes; VSV, vesicular stomatitis virus.

Conflict of interest: The authors have declared that no conflict of interest exists. Citation for this article: J. Clin. Invest. 116:1254-1263 (2006). doi:10.1172/JCI27372. viduals (14) with predisposition to disease. The finding of a similar seasonal peak in disease onset lent support to the hypothesis that an independent infectious event precipitates disease (15), potentially after a long phase of subclinical progression $(10,16)$.

Another autoimmune syndrome that often follows an infectious episode is rasmussen encephalitis (RE; ref. 17). RE is manifested by epileptic seizures that are refractory to antiepileptic drugs and ultimately require the surgical removal of affected brain regions. The histological picture of affected brain regions is dominated by infiltrating $\mathrm{CD}^{+} \mathrm{T}$ lymphocytes that are often found in direct contact with neurons (18). Infiltrating CTLs exhibit biased receptor usage indicative of an antigen-specific process and currently represent the most likely mediators of RE (19). The histomorphological similarity to viral encephalitis had long ago fostered speculations about an underlying viral pathogenesis in RE (17). Over time enteroviruses, Epstein-Barr virus, herpes simplex virus 1, and also cytomegalovirus have been detected in affected brain tissue (19). Final proof for an infectious culprit is, however, missing, as it is for all the other autoimmune diseases with a suspected viral pathogenesis.

Experimentally, a number of concepts could explain virus-induced, organ-specific, T cell-mediated diseases. They include molecular mimicry of self structures by pathogens (20), T cell epitope spreading to tissue-specific self epitopes upon virus-mediated tissue destruction (21) and bystander activation of autoreactive T cells (22). Furthermore, autoreactive $T$ cells induced by molecular mimicry of self or in a bystander fashion may require subsequent triggering by nonspecific inflammatory stimuli to cause an autoaggressive disorder (fertile field hypothesis; ref. 23). Models for these not mutually exclusive mechanisms have provided key insights into the molecular mechanisms of immune-mediated tissue damage and will undoubtedly help to develop therapies aimed at interfering with these processes (24). It is still debated, however, to what extent these models recreate the pathogenesis of human autoimmune diseases (25). Importantly, 
A
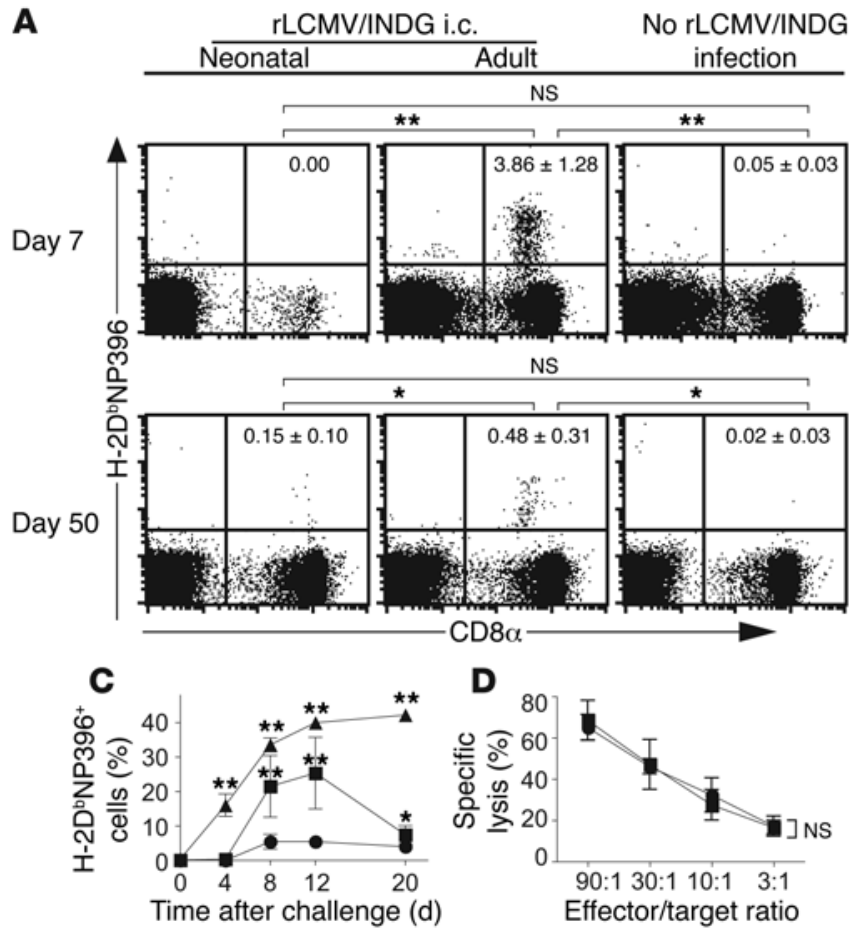

B
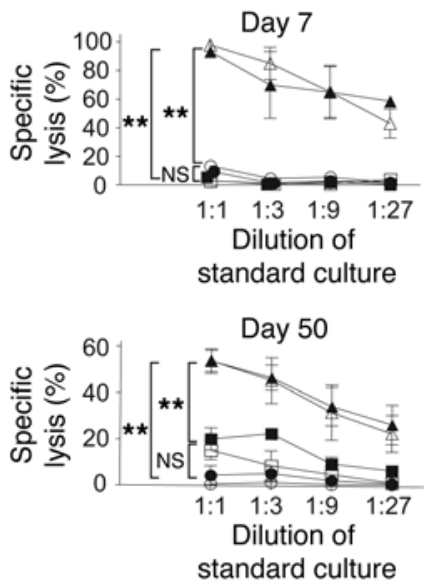

4- rLCMV/INDG i.c. adult

- rLCMV/INDG i.c. neonatal

- No rLCMVIINDG infection

Figure 1

Inefficient induction of virus-specific CD8+ T cells in rLCMV/INDG carriers. (A) Neonatal and adult C57BL/6 mice were infected with rLCMV/INDG i.c. or were left uninfected. On days 7 and 50, NP396-specific CD8 ${ }^{+}$ $\mathrm{T}$ cells in the spleen (day 7) and blood (day 50) were enumerated by flow cytometry using MHC class I tetramers (H-2D $\left.{ }^{\mathrm{b}} \mathrm{NP396}\right)$. Numbers indicate percentages of NP396-specific CD8 ${ }^{+}$cells within the CD8 ${ }^{+}$ T cell compartment (mean \pm SD of 3-4 mice). (B) Neonatal (rectangles) or adult (triangles) C57BL/6 mice were infected with rLCMV/INDG i.c. or were left uninfected (circles). Mice were sacrificed 7 and 50 days later, and NP396-specific CTL activity was determined after in vitro restimulation of splenocytes in the presence (filled symbols) or absence (open symbols) of rIL-2. Shown are mean \pm SEM of 3-4 mice per group. Cultures with rlL-2 were not significantly different from cultures without rlL-2 (not shown). (C) Mice were challenged with ARM i.v. 50 days after infection as described above. The frequency of NP396-specific $\mathrm{CD}^{+} \mathrm{T}$ cells in blood was measured using MHC class I tetramers. Values differing significantly from those of ARM-challenged mice without prior rLCMV/INDG infection (circles) are indicated. (D) rLCMV/INDG carrier mice (50 days old) and naive adult control mice were challenged with ARM i.v. Seven days later mice were sacrificed, and the NP396-specific primary ex vivo CTL activity of splenocytes was measured. Shown are mean \pm SEM of 3 mice. Specific lytic activity of naive control splenocytes was $<3 \%$ (not shown). Most panels are representative of 2 similar experiments. ${ }^{*} P<0.05 ;{ }^{* *} P<0.01$.

all these postulates rely on bona fide self-reactive $T$ cells, but the need to break tolerance to self conflicts somewhat with the recent finding that thymic $\mathrm{T}$ cell tolerance extends to many tissue-specific self antigens (26). Moreover, it is still poorly understood how predisposition to disease is acquired during a phase of susceptibility in early childhood despite the lack of temporal association with disease onset $(2,10,12,13)$. We therefore reinvestigated immunological tolerance against neonatal viral infections $(27,28)$ as a putative link between early childhood infections and organ-specific immune diseases.

Intracerebral (i.c.) neonatal infection ( $<24$ hours after birth) of mice with naturally occurring strains of lymphocytic choriomeningitis virus (LCMV; naturally occurring strain referred to as LCMVwt) is widely used to study viral persistence (27). Systemic infection involves the neonatal thymus (29) and results in central antiviral $\mathrm{CD} 8^{+} \mathrm{T}$ cell tolerance. This prevents cytotoxic $\mathrm{T}$ cell-mediated (CTL-mediated) disease in neonatally infected virus carriers and, together with noncytolytic behavior of LCMV in vivo, allows for lifelong viral persistence. In contrast, i.v. infection of adult anishowed specific $\mathrm{T}$ cell frequencies around the detection limit (Figure $1 \mathrm{~A}$ and data not shown). In some experiments, a slight elevation over background levels appeared as a trend that was not statistically significant. CTL assays after in vitro restimulation with peptide in the presence or absence of exogenous rIL-2 yielded analogous results (Figure 1B). Together these findings rendered the presence of a substantial population of NP396-specific $\mathrm{CD}^{+} \mathrm{T}$ cells unlikely. As positive control, we inoculated adult mice i.c. with the same dose. Unlike LCMVwt strains (32), adult i.c. infection with rLCMV/ INDG did not result in lethal $\mathrm{CD}^{+} \mathrm{T}$ cell-mediated choriomeningitis. Rather, rLCMV/INDG was cleared from the brain in a clinically silent fashion (Supplemental Figure 1; supplemental material available online with this article; doi:10.1172/JCI27372DS1) that was T cell dependent (D. Merkler and D.D. Pinschewer, unpublished observations). At the peak of the response, approximately $4 \%$ of the circulating $\mathrm{CD}^{+} \mathrm{T}$ cells were NP396 specific, and longlived CTL memory was induced (Figure 1, A and B, and data not shown), confirming our previous observation that rLCMV/INDG 
A

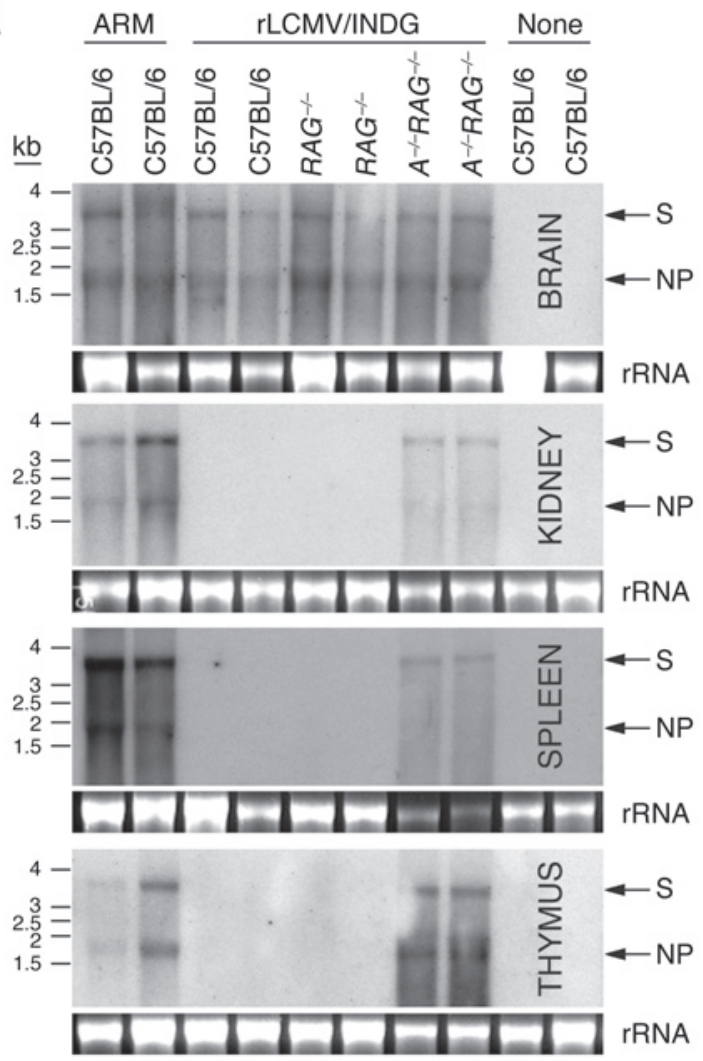

B
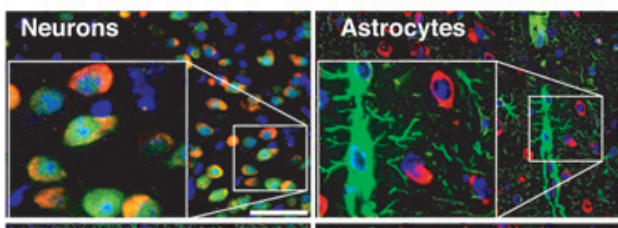

Oligodendrocytes

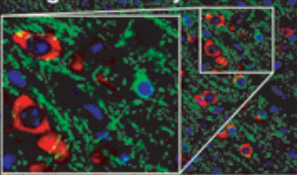

Endothelia

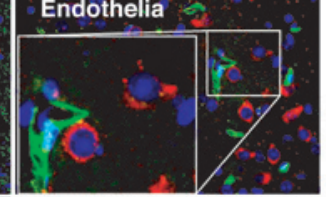

Microglia/macrophages

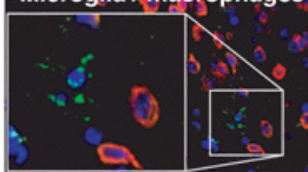

\section{Figure 2}

Persistence of rLCMV/INDG is restricted to CNS neurons. (A) C57BL/6, $R A G^{-1-}$, and $A^{-1-} R_{A G}{ }^{-/-}$mice were infected at birth with ARM or rLCMV/ INDG i.c. or were left uninfected. At 35-50 days of age, the indicated organs were tested for viral S segment and NP mRNA by Northern hybridization (ethidium bromide staining of $28 \mathrm{~S}$ rRNA is shown as loading control). An analogous pattern of rLCMV/INDG distribution in the body was observed in various experiments with neonatally infected C57BL/6, $R A G^{-/-}$, and $A^{-/-} R A G^{-1-}$ mice (8-10 mice per genotype). (B) Brain sections of neonatally rLCMV/INDG infected 5- to 7-week-old C57BL/6 mice were costained for LCMV-NP (red), nuclei (blue), and cell type-specific markers (green) as indicated. Scale bar: $50 \mu \mathrm{m}$. Insets show 2.5-fold-higher-magnification views of boxed regions. Representative images show neuron-restricted virus distribution as found in the entire CNS ( $n=9$ animals from 3 independent experiments with identical results; for overview images see Supplemental Figure 5).

was a potent trigger for $\mathrm{CD}^{+} \mathrm{T}$ cells of adult mice (31). Thus the response in newborn animals would have been in keeping with neonatal antiviral tolerance by clonal deletion. Yet our observations could also have reflected inefficient induction of the $\mathrm{CD}^{+} \mathrm{T}$ cell response as previously observed in other clinical and experimental settings of neonatal exposure to viral infection and foreign tissue, respectively $(28,33)$. To differentiate between these possibilities, we challenged 50-day-old rLCMV/INDG carriers, mice immunized as adults with rLCMV/INDG via the i.c. route (referred to as rLCMVINDG-immune), and naive adult controls with the LCMVwt strain Armstrong (ARM) i.v. (Figure 1, C and D). Four days later, adult rLCMV/INDG-immune mice, but not carriers or previously naive controls, exhibited a recall response; however, by day $8, \mathrm{rLCMV} /$ INDG carrier mice showed high frequencies of NP396-specific CD8 ${ }^{+}$

\section{Table 1}

Absence of detectable infectivity in the serum of RAG-deficient rLCMV/INDG carriers

\begin{tabular}{|c|c|c|c|c|c|c|c|}
\hline \multirow[b]{2}{*}{ Genotype of serum donor } & \multicolumn{4}{|c|}{ rLCMV/INDG carrier serum } & \multicolumn{2}{|c|}{ Cell culture-derived virus } & No inoculation \\
\hline & $A^{-/-} R A G^{-/-}$ & $R A G^{-/-}$ & $R A G^{-/-}$ & $R A G^{-/-}$ & NA & NA & NA \\
\hline Infectivity of inoculum (PFU)A & 50 & $<2$ & $<2$ & $<2$ & 10 & 1 & NA \\
\hline Antibody response (titer, mean $\pm \mathrm{SD})^{\mathrm{B}}$ & $8 \pm 1$ & $<1$ & $<1$ & $<1$ & $6.7 \pm 0.6$ & $4.7 \pm 1.2$ & $<1$ \\
\hline CTL response $(\% \text {, mean } \pm \text { SD })^{\mathrm{C}}$ & $5.0 \pm 0.9$ & $0.003 \pm 0.006$ & $0.006 \pm 0.005$ & $0.01 \pm 0.02$ & $2.8 \pm 0.7$ & $1.3 \pm 0.4$ & $0.01 \pm 0.01$ \\
\hline
\end{tabular}

Groups of 3 C57BL/6 mice were inoculated i.c. either with serum of rLCMV/INDG carrier mice of $A^{-/-} R A G^{-/-}$or $R A G^{-/-}$genotype or with cell culture-derived virus (positive control) or they were not inoculated (naive control). Four individual rLCMV/INDG carriers (neonatally infected) served as donors of serum. AInfectivity of the 30- $\mu$ l i.c. serum was assessed by tissue culture immunofocus assay, with a detection limit of 50 PFU/ml ( 2 PFU/30 $\mu$ l). Infectivity in cell culture-derived viral inocula was calculated based on the viral stock titer and the dilutions made. BSeven days after inoculation, serum samples were collected and tested in neutralization assays. Titers were calculated as $\left(-\log _{2}\right)$ of 40 -fold prediluted serum. ${ }^{C}$ Seven days after inoculation, the frequency of NP396-specific CD8+ T cells in blood was determined by MHC class I tetramer staining. Analogous antibody and CTL response results were obtained on day 14 after inoculation (not shown). 

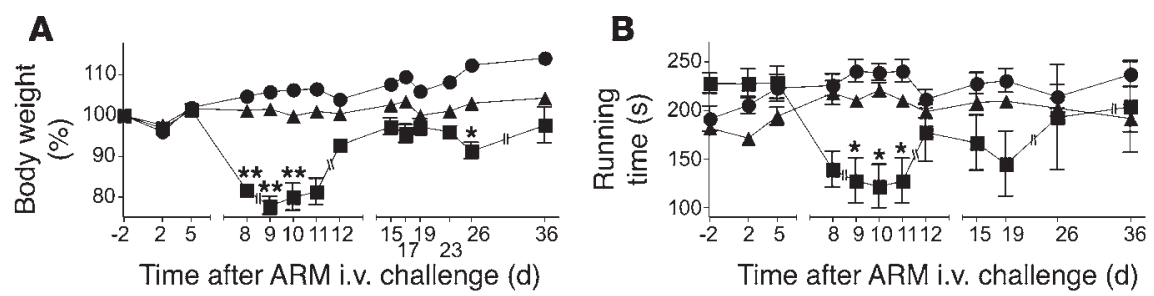

× rLCMV/INDG i.c. adult

- rLCMV/INDG i.c. neonatal

- No previous infection

\section{Figure 3}

Weight loss and impaired motor coordination in ARM-challenged rLCMV/INDG carriers. On day -50 , neonatal (rectangles) and adult (triangles) C57BL/6 mice were infected with rLCMV/INDG i.c., resulting in rLCMV/INDG carriers and rLCMV/INDG-immune mice, respectively. A control group of adult mice without rLCMV/INDG infection (circles) was also included. All mice were challenged with ARM i.v. on day 0. (A) Body weight was monitored at the indicated time points. (B) Motor coordination was tested on a rotating rod, and the running time was recorded. Shown are the mean \pm SEM of 10-11 mice initially; due to terminal disease, individual rLCMV/INDG carriers had to be euthanized on days 8,11 (3 mice), 17, and 26 after ARM challenge (broken lines). ${ }^{*} P<0.05$, ${ }^{* *} P<0.01$ compared with the respective group's highest value prior to disease onset.

CNS (Supplemental Figure 3A), similar to WT mice, indicating that adaptive immune mechanisms could compensate for the lack of type I IFN effects. In support of this we found that the serum of $A^{-/-}$rLCMV/INDG carriers exhibited INDG-specific neutralizing activity at a titer of approximately 1:10,000 (data not shown). This rendered $\mathrm{rLCMV} / \mathrm{INDG}$ carrier $A^{-/-}$mice resistant to challenge with VSV serotype Indiana (VSVIND) at greater than 10,000 times the lethal dose, a well-established readout system for antibody-mediated protection (ref. 31 and Supplemental Figure 3B). To address the question of whether antibodies are necessary to prevent significant spillover of virus from the brain into the periphery of type I IFN receptor-competent mice, we performed serum transfer experiments. Inoculation i.c. of adult C57BL/ 6 mice with $\mathrm{rLCMV} / \mathrm{INDG}$ represented a sensitive readout system for even low amounts of infectivity ( 1 PFU) by

$\mathrm{T}$ cells, ruling out deletion of the virus-specific CTL repertoire as observed after neonatal ARM infection (Figure 1C). Moreover, these cells were fully functional, as determined in a primary ex vivo CTL assay (Figure 1D). The rapidity of onset and the overall course of the $\mathrm{CD}^{+} \mathrm{T}$ cell response in $\mathrm{rLCMV} / \mathrm{INDG}$ carrier mice were not significantly different from previously naive control mice, as assessed by repeated-measures ANOVA (Figure 1C). In rLCMV/INDG carrier mice, however, NP396-specific $\mathrm{CD}^{+} \mathrm{T}$ cell frequencies at days 8,12 , and 20 after ARM challenge were significantly higher than in previously naive mice (Figure 1C). This suggested prior induction of NP396-specific CD8 ${ }^{+} \mathrm{T}$ cells, albeit to such a low degree that they escaped detection in the experiments shown in Figure 1, A and B, and had only become apparent upon secondary infection with ARM. Yet viral challenge experiments failed to demonstrate protection by putative $\mathrm{CD}^{+}$memory T cells (Supplemental Figure 2), confirming that most rLCMV/INDG carrier mice had an NP396-specific CD8 ${ }^{+}$ $T$ cell repertoire that was neither deleted nor sufficiently induced to confer protective antiviral immunity.

Innate immunity is sufficient to restrict $r L C M V / I N D G$ persistence to CNS neurons. To understand how $\mathrm{CD}^{+}$precursor $\mathrm{T}$ cells could have been blinded to the persistent rLCMV/INDG infection in a way that they were neither deleted in the thymus nor efficiently induced in secondary lymphoid organs, we analyzed the viral distribution in the host. Unlike ARM carrier mice, viral RNA was found in brain but not in kidney, spleen, or thymus of C57BL/ 6 rLCMV/INDG carrier mice (Figure 2A; analogous findings in BALB/c and $129 \mathrm{~Sv}$ mice not shown). The $R A G^{-/-}$rLCMV/INDG carriers exhibited the same distribution, indicating that adaptive immune responses were not required for CNS restriction. Only in rLCMV/INDG carrier mice with a deletion of the type I IFN receptor gene in addition to deletion of the RAG gene $\left(A^{-/-} R A G^{-/-}\right.$mice; ref. 34) was viral RNA found in all organs tested and the serum infectious (Figure 2A and Table 1). This was in accordance with the pantropic nature of INDG and indicated that CNS restriction of rLCMV/INDG in carrier mice was not due to viral receptor tropism but was a result of innate immune control outside the CNS. Experiments in type IIFN receptor-deficient but RAG-competent $\left(A^{-/-}\right)$mice have shown that persistent infection with $\mathrm{rLCMV} / \mathrm{INDG}$ was also restricted to the eliciting vigorous $\mathrm{B}$ and $\mathrm{T}$ cell responses (Table 1). Yet the transfer of serum from $R A G^{-1-}$ rLCMV/INDG carriers i.c. into naive C57BL/6 mice failed to elicit a detectable antiviral CTL or antibody response, whereas $A^{-/-} R A G^{-/-}$serum was highly immunogenic (Table 1 ). An assessment of viral infectivity in the sera by immunofocus assay yielded analogous results, confirming that even in $R A G^{-/-}$mice that lack antibodies, the persistently infected CNS released at best very little virus (Table 1). In support of this notion we found also that in B cell-deficient $\mu M T$ mice, antiviral CTLs were no more efficiently induced than in C57BL/6 mice (Supplemental Figure 3C). Thus type I IFN-mediated containment of rLCMV/INDG within the CNS was a plausible explanation for why virus-specific CTLs of rLCMV/ INDG carriers were neither clonally deleted nor efficiently induced prior to ARM challenge, but additional mechanisms could also be envisaged (see Discussion). Immunohistochemical analysis of brain and spinal cord (Figure 2B; for overview images, see Supplemental Figure 4) revealed that neurons of rLCMV/INDG carriers expressed viral antigen, while virus was undetectable in oligodendrocytes, astrocytes, endothelial cells, or microglia. Yet restriction to neurons as well as regional distribution of rLCMV/INDG within the CNS were unaltered in $A^{-/-} R A G^{-/-}$mice (Supplemental Figures 5 and 6). This indicated that unlike viral restriction to the CNS, neither adaptive immune control nor type I IFN signaling - rather other as-yet undefined mechanisms - were responsible for the observed virus distribution and cell tropism within the CNS.

Viral déjà vu elicits CNS immune disease. In the experiments shown in Figure 1C, we observed that ARM challenge of rLCMV/INDG carriers caused sudden weight loss and general malaise, while both control groups remained healthy. The disease started approximately 7 days after the second viral exposure, peaking around days 8-12 (Figure 3A). Behavioral analysis with a rotating rod (Figure $3 \mathrm{~B}$ ) revealed that motor coordination and balance were impaired, suggesting an underlying CNS process. The phenomenon was highly reproducible and required euthanasia of up to $50 \%$ of rLCMV/INDG carrier mice. Some variability in the severity of disease was, however, not surprising in the light of analogous findings with other models for CNS immune disease. In accordance with healthy appearance (30) and unimpaired motor func- 
A

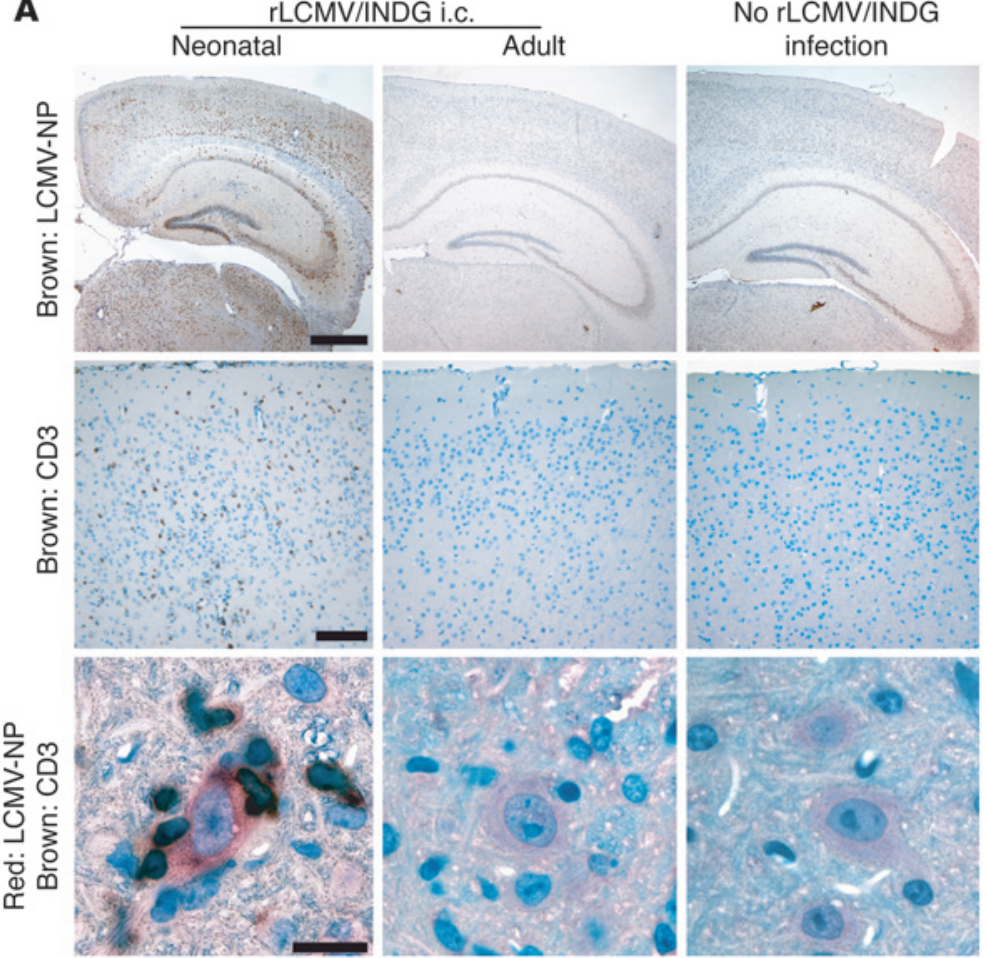

B RE (human)
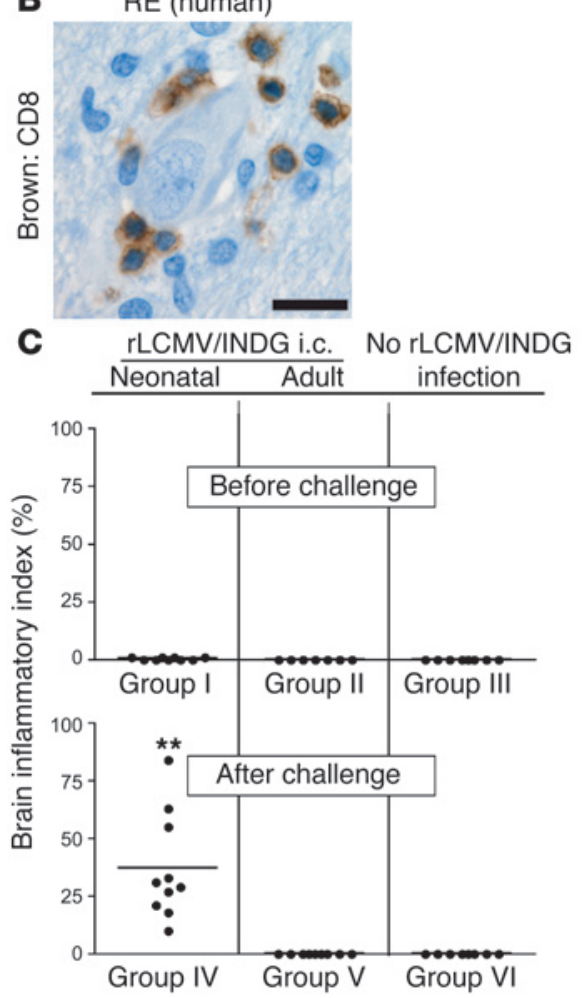

Figure 4

T cell infiltration in the brains of ARM-challenged rLCMV/INDG carriers. (A) Neonatal and adult C57BL/6 mice were infected at day -50 with rLCMV/INDG i.c., resulting in rLCMV/INDG carriers and rLCMV/INDG-immune mice, respectively. On day 0 , these animals and a control group of adult mice without rLCMV/INDG infection were challenged with ARM i.v. Brain (top and center panels) and spinal cord sections (bottom panel) were prepared 8 days after ARM challenge and stained for LCMV-NP and CD3+ T cells. Representative images of 7-10 mice per group are shown. Scale bars: 500 um (top); 100 um (center); 20 um (bottom). (B) Brain biopsy of a human patient with RE. A representative neuron surrounded by CD8 ${ }^{+} \mathrm{T}$ cells (brown) is shown. Scale bar: $20 \mu \mathrm{m}$. (C) C57BL/6 mice were infected with rLCMV/INDG as in A and sacrificed either immediately preceding ARM challenge 50 days later (groups I-III) or 8-12 days after ARM challenge (the peak of disease in rLCMV/INDG carriers; groups IV-VI) to determine the brain inflammatory index. Symbols represent individual mice from a total of 3 independent experiments; horizontal lines indicate means. Neonatally rLCMV/INDG-infected mice after ARM i.v. challenge (Group IV) exhibited dense T cell infiltration in brain, whereas the remaining groups were statistically indistinguishable from each other. Analogous results were also obtained for spinal cord (not shown). ${ }^{* \star} P<0.001$ versus all other groups.

tion (Figure 3B), histological analysis of brain and spinal cord of rLCMV/INDG carriers prior to ARM i.v. challenge showed only background $\mathrm{T}$ cell infiltration (summarized in Figure 4C). Upon ARM challenge, however, dense and widespread inflammatory infiltrates were found within the gray matter of brain as well as spinal cord (Figure 4, A and C, and data not shown). Infiltrates in the 2 control groups were in the background range regardless of challenge with ARM. Thus clinical and histological disease correlated strictly with persistent LCMV antigen only in rLCMV/INDG carriers (predisposing virus) and with secondary ARM challenge (precipitating virus) of these mice (Figure 4, A and C, and data not shown). Brain-infiltrating $\mathrm{CD}^{+} \mathrm{T}$ cells of ARM-challenged rLCMV/INDG carriers expressed perforin in situ, and lymphocytes isolated from such brains lysed NP396-coated target cells in vitro with very high efficiency (Figure $5, \mathrm{~A}$ and $\mathrm{B}$ ). $\mathrm{CD}^{+} \mathrm{T}$ cells dominated the brain infiltrate of ARM-challenged rLCMV/INDG carriers, outnumbering $\mathrm{CD}^{+} \mathrm{T}$ cells by about 10 -fold (Figure $5 \mathrm{C}$ ), and the majority produced IFN- $\gamma$ in response to NP396 stimulation (Figure 5D). Thus the immunoprivileged milieu of the brain failed to render infiltrating CTLs unresponsive.
Interestingly, the histological picture of this inflammatory process exhibited striking histomorphological similarities to human RE (compare Figure 4A with Figure 4B) (18). In both diseases the CNS infiltrate consisted largely of $\mathrm{CD}^{+} \mathrm{T}$ cells that appeared to be in contact with neurons. Yet the specificity of $\mathrm{CD}^{+} \mathrm{T}$ cells associated with gray matter neurons of RE patients (18) remains unknown and is widely assumed to be autoreactive. In our model, though, LCMV antigen-positive neurons of ARM-challenged rLCMV/INDG carriers were preferentially surrounded by $\mathrm{T}$ cells (Figure 4A). When counting T cells in direct contact with a neuron, 94 of $117 \mathrm{~T}$ cells $(\sim 80 \%)$ in 4 representative animals were associated with an LCMV antigen-positive neuron. Considering that less than $50 \%$ of all neurons were rLCMV/INDG infected, this suggested that $\mathrm{T}$ cells specifically recognized viral epitopes on infected neurons and argued against self reactivity as an underlying mechanism of disease. Nevertheless, this did not directly demonstrate the contribution of these cells to disease, nor could we rule out yet that nonspecific virus-induced inflammation rather than viral antigen attracted effector $\mathrm{T}$ cells to the site of rLCMV/INDG persistence. 

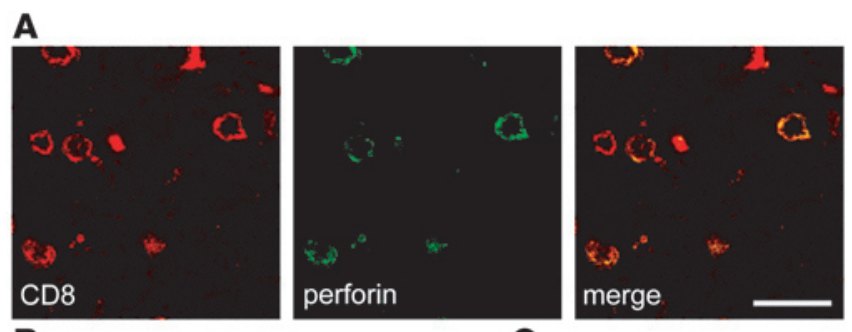

B

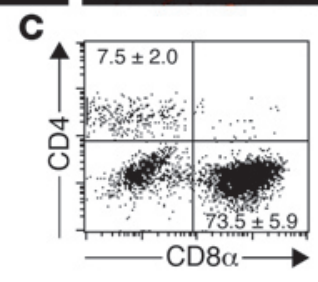

D

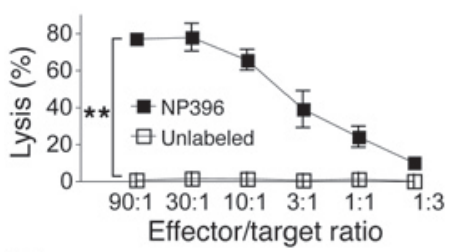

NP396-stimulated

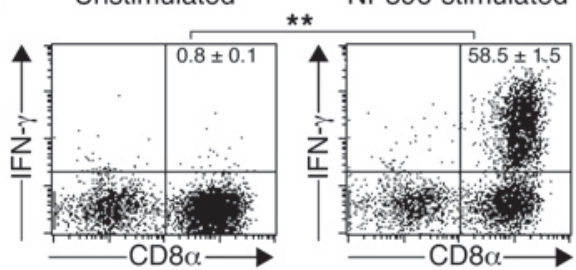

A single dominant specificity of antiviral CTL causes viral déjà vu disease. To experimentally address the question of how viral déjà vu precipitated CNS immune disease we considered that the CTL response to ARM predominantly targets the viral GP and NP proteins. Only the NP gene, not the GP gene, is shared between $\mathrm{rLCMV} / \mathrm{INDG}$ persisting in brain and ARM precipitating disease (30). Thus, NP-specific but not LCMV-GP-specific CTLs should have been able to cause disease if indeed persisting rLCMV/INDG antigen represented the target of CNS-infiltrating CTLs. In contrast, bystander damage of rLCMV/ INDG-infected neurons should not have occurred in a viral genespecific manner. We therefore tested the hypothesis that NP396, the immunodominant $\mathrm{H}-2 \mathrm{D}^{\mathrm{b}}$-restricted, NP-derived epitope, was the primary target of the pathogenic CTL response. For this purpose, rLCMV/INDG carrier mice were either rendered tolerant to NP396 by peptide treatment (35) or they were given diluent only as a control prior to ARM i.v. challenge. Tolerization reduced the ensuing response against NP396 (the major CTL epitope shared between rLCMV/ INDG and ARM) to background levels, whereas the response to the immunodominant LCMV-GP-derived H-2 $\mathrm{D}^{\mathrm{b}}$-restricted CTL epitope GP33 (not shared by rLCMV/INDG) and to subdominant NP- and GP-derived epitopes remained unimpaired or were even enhanced (Figure 6A and data not shown). This latter effect was likely due to the absence of competing NP396-specific CTL (36). Unlike controls treated only with diluent, NP396-tolerized rLCMV/INDG carriers remained clinically healthy and exhibited no weight loss (Figure 6B). Motor coordination remained unimpaired apart from a transient, modest reduction around day 8 after challenge that failed to reach statistical significance (Figure 6C). Unlike in control mice, this slight dip was reversible by day 9-10 and in some experiments was also observed in previously naive mice infected with ARM i.v. (data not shown). Histological analysis at the peak of disease indicated that LCMV antigen levels were identical in both groups (Figure 6D). But compared with diluent-treated control mice, NP396 tolerization reduced $\mathrm{T}$ cell infiltrates in brain and spinal cord from $331 \pm 155$

\section{Figure 5}

Virus-specific effector function of brain-infiltrating CD8 ${ }^{+} \mathrm{T}$ cells. rLCMV/ INDG carrier mice (50 days old) were challenged with ARM i.v. At the peak of disease 9 days later, brain tissue was processed for extraction of lymphocytes or for histological analysis of the infiltrate. (A) Braininfiltrating T cells were stained for CD8 (red) and perforin (green) and were analyzed by confocal microscopy. Images are representative of multiple sections from at least 3 different animals. (B) Primary ex vivo CTL activity of brain-extracted lymphocytes on NP396-pulsed or unlabeled target cells. (C) Brain-infiltrating lymphocytes were analyzed by flow cytometry for surface expression of CD4 and CD8 $\alpha$. The percentage of single-positive cells is indicated (mean \pm SD of 3 mice). (D) Brain-extracted lymphocytes were restimulated with NP396 peptide or with medium only (unstimulated), and IFN- $\gamma$-producing cells were enumerated by flow cytometry. Shown are percentages of IFN- $\gamma-$ producing cells among CD8 ${ }^{+} \mathrm{T}$ cells (mean \pm SD of 3 mice per group). One representative of 2 similar experiments is shown. Of note, the absence of infiltrates in naive mice and in rLCMV/INDG-immune mice challenged with ARM (see Figure $4 \mathrm{~A}$ ) rendered analogous tests for these groups impossible. ${ }^{* *} P<0.01$.

to $10 \pm 4$ and from $250 \pm 157$ to $8 \pm 3$ cells $/ \mathrm{mm}^{2}$ (mean $\pm \mathrm{SD} ; P<0.01$ ), respectively (Figure 6D and data not shown). Thus abrogation of CNS inflammation and clinical disease by NP396 tolerization demonstrated that the autoimmune-like disease in ARM-challenged rLCMV/INDG carriers was mediated by virus-specific (NP396) CTL. Taking into consideration that NP396 reactivity did not cause CNS inflammation in mice lacking viral antigen in neurons (e.g., in naive mice or in rLCMV/INDG-immune mice challenged with ARM; compare Figure 3 with Figure 4, A and B), abrogation of disease by NP396 tolerization excluded a viral mimic of self as a potential underlying mechanism. Therefore, the disease observed in i.v. ARM-challenged rLCMV/INDG carrier mice was due to the now efficient induction of NP396-specific $\mathrm{CD}^{+} \mathrm{T}$ cells that homed to the brain and targeted rLCMV/INDG in persistently infected neurons. These conclusions were independently corroborated in adoptive transfer experiments (see Supplemental Results and Supplemental Figure 7).

Secondary infection with an unrelated virus fails to elicit disease. Our experiments based on NP396 peptide tolerization (Figure 6) indicated that virally induced inflammation was insufficient - although likely necessary - to trigger inflammatory CNS disease in rLCMV/INDG carriers. To confirm that antigenic determinants shared between the persisting virus in CNS (rLCMV/INDG) and the acutely infecting virus in the periphery (ARM) represented a requirement for inflammatory CNS disease, rLCMV/INDG carriers were challenged either with ARM as positive control or with a genetically engineered rVSV expressing the LCMV-GP instead of INDG (rVSV/LCMV-GP; ref. 31). This virus therefore binds to the same cellular receptor as ARM, without however sharing antigenic determinants with rLCMV/ INDG persisting in the CNS (31). Unlike ARM challenge, adult infection of rLCMV/INDG carriers with rVSV/LCMV-GP did not cause weight loss, impaired motor coordination, or $\mathrm{T}$ cell infiltration of the CNS (Figure 7). Analogous results were also obtained when vaccinia virus was used as a precipitating virus (data not shown). Thus virus-induced inflammation alone was insufficient to trigger CNS immune disease in rLCMV/INDG carriers.

\section{Discussion}

Viral déjà vu disease results from a defined chronology of antigenically related viral infections. ARM or rLCMV/INDG infection of naive mice did not cause disease, and rLCMV/INDG challenge of neona- 

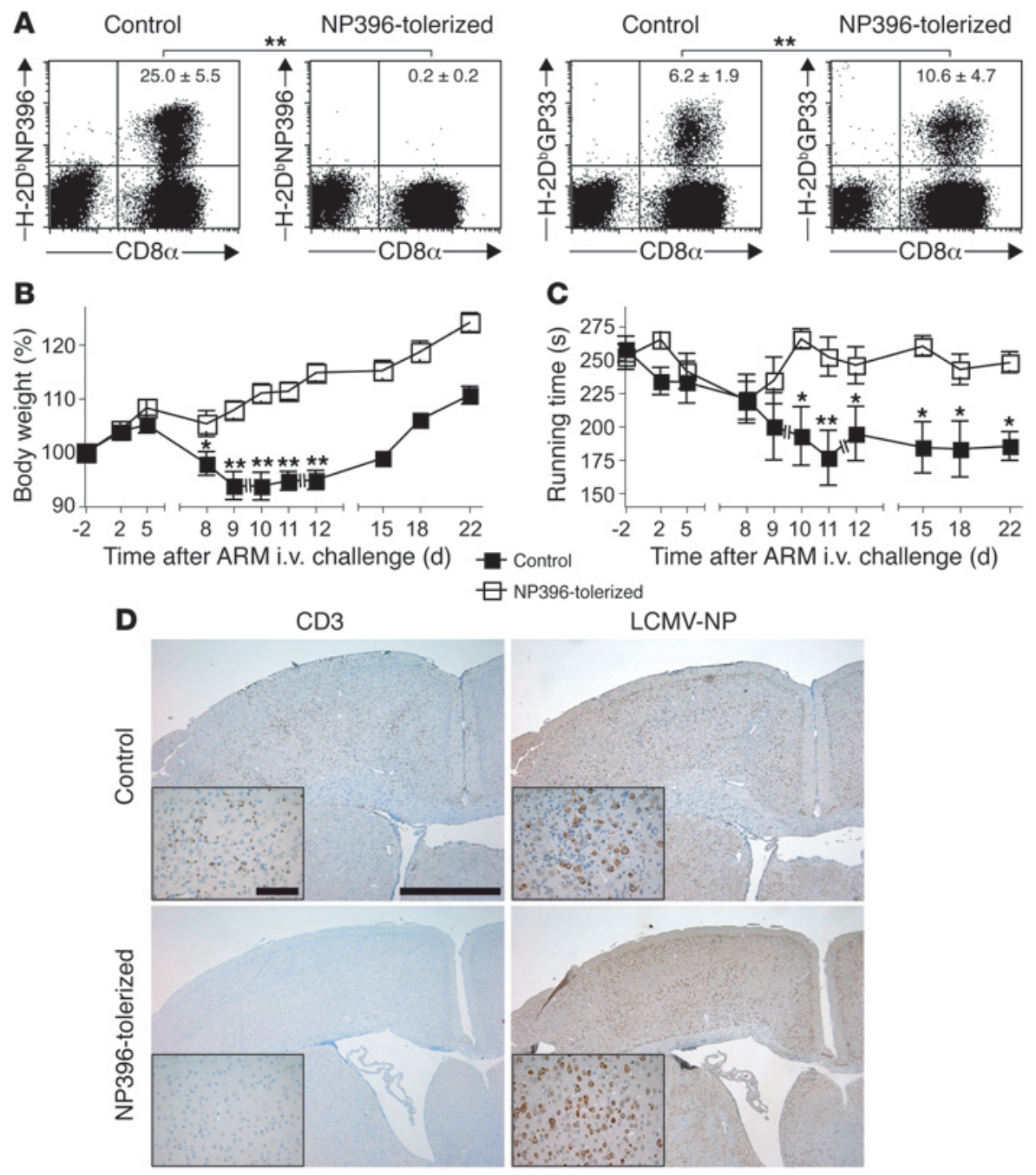

\section{Figure 6}

CNS disease is mediated by a single dominant specificity of antiviral CTL. rLCMV/ INDG carriers (50 days old) were either tolerized to NP396 by peptide treatment (open rectangles) or given diluent only (filled rectangles). On day 0 , both groups of mice were challenged with ARM i.v. (A) The percentage of NP396- and GP33-specific $\mathrm{CD}^{+} \mathrm{T}$ cells in blood was measured on day 8 and is shown in each representative flow cytometry plot (mean $\pm \mathrm{SD}$ of $\geq 3$ mice per group). ${ }^{*} P<0.01$. (B and C) The body weight (B) and motor coordination (C) of the same mice as in $\mathbf{A}$ were monitored. Shown are the mean \pm SEM of initially 10 mice per group; due to severe illness, 2 nontolerized mice had to be euthanized on days 9 and 11 after ARM challenge (broken lines). ${ }^{*} P<0.05$, ${ }^{\star \star} P<0.01$ compared with highest value prior to disease onset. (D) Separate groups of mice treated as in $\mathbf{A}-\mathbf{C}$ were sacrificed on day 8 after ARM challenge. Brain-infiltrating $T$ cells (CD3) and persistent rLCMV/INDG (LCMV-NP) were assessed by histological analysis. Images are representative of histological sections of 3 mice per group. One representative of 2 similar experiments is shown. Scale bars: $1 \mathrm{~mm} ; 100 \mu \mathrm{m}$ (insets). tally infected ARM carriers was clinically silent (data not shown), most likely due to antiviral CD8 ${ }^{+} \mathrm{T}$ cell tolerance $(27,28)$. Moreover, rLCMV/INDG persisted in the CNS of carriers at comparable levels for at least 100 days (as determined by immunohistochemistry; data not shown) and remained restricted to neurons. Yet disease was not observed in the absence of ARM challenge.

A schematic of the viral déjà vu pathogenetic mechanism is presented in Figure 8. Organ-restricted viral persistence may result from an infection encountered in neonatal life (33) or simultaneously with a second immunosuppressive infection (e.g., measles or herpesviruses; ref. 37). Under such circumstances, the virus may initially spread throughout the body but innate immune mechanisms such as type I IFNs, possibly aided by antibodies, may be sufficient to clear the virus from most tissues. Owing to an inefficient $T$ cell response, virus may though persist in particular sites (predisposing virus). Neonatal rLCMV/INDG infection created a similar situation. It is well established that the majority of an i.c. inoculum is rapidly drained to the bloodstream (38), creating in essence a systemic infection with involvement of the CNS. This was reflected here in the antiviral antibody response of newborns (Supplemental Figure 3B and Supplemental Figure 8) and also in the potent $\mathrm{CD}^{+} \mathrm{T}$ cell response in adult i.c. infected mice (Figure 1). Under natural conditions of a systemic infection, viruses may profit from the immature blood-brain barrier of neonates to enter the CNS via the blood. Alternatively, they may access the CNS via peripheral nerves (analogous to rabies virus) or via the olfactory system (respiratory infections). Thus the initial route of neuroinvasion may determine a discrete site of immune disease triggered years or even decades later upon viral déjà vu. Preliminary data obtained with rLCMV/INDG indicate that in a small proportion of animals, vertical transmission or mucosal infection via the neonate's nose can also result in persistent infection that is then restricted to the CNS (data not shown). Owing to the relatively low frequency of these events in our experimental system, however, these routes of infection could not be exploited for the present study.

The viral déjà vu model and transgenic mice with tissue-specific expression of a viral neo-self antigen (molecular mimicry; refs. 23, $24,39)$ share a characteristic trait: In both cases, a viral infection can elicit $\mathrm{T}$ cell-mediated damage to specific organs. There are, however, fundamental differences between molecular mimicry and our viral déjà vu postulate that have wide-ranging implications:

First, molecular mimicry implies that similar epitopes are shared between a virus and the host (i.e., pathogen-host mimicry) and that virus-induced $\mathrm{T}$ cells therefore recognize and damage cells expressing self $(23,24,39)$. In contrast, viral déjà vu is based on an epitope shared between 2 related viruses (i.e., pathogen-pathogen mimicry or simply antiviral cross-reactivity), representing a relatively fre- 

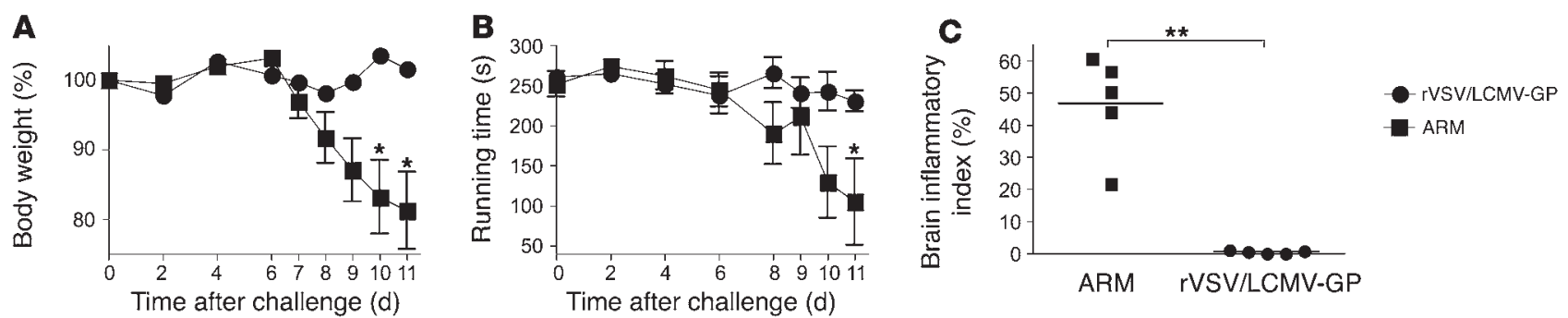

Figure 7

Absence of inflammatory CNS disease in rLCMV/INDG carriers challenged with rVSV/LCMV-GP instead of ARM. rLCMV/INDG carriers (50 days old) were challenged either with ARM or with rVSV/LCMV-GP i.v. (A and B) Body weight (A) and running time on the rotating rod (B) were monitored at the indicated time points after ARM challenge. Shown are the mean \pm SEM of 5 mice per group. ${ }^{\star} P<0.05$ compared with highest value prior to disease onset. (C) At the peak of disease in ARM-challenged animals (day 11), all mice were sacrificed, and the brain inflammatory index was determined. Symbols represent individual mice; horizontal lines indicate means. ${ }^{* *} P<0.01$.

quent finding (40). In this setting, tissue damage is therefore mediated by antiviral CTLs targeting viral non-self. This difference is important since $\mathrm{CD}^{+}$precursor $\mathrm{T}$ cells specific for bona fide self (including transgenic neo-self antigens) are potentially subject to autoimmune regulator-dependent (AIRE-dependent) mechanisms of thymic tolerance (26). In contrast, thymic medullary epithelial cells of rLCMV/INDG carriers lack the viral genetic information and cannot negatively select virus-specific $\mathrm{CD} 8^{+}$precursors. Hence, viral déjà vu - but not molecular mimicry - circumvents AIREmediated central tolerance mechanisms.

Second, persisting virus as a target of immune attack (viral déjà vu) offers entirely different options for prevention, treatment, and early diagnosis than does an immune disease targeting self (molecular mimicry). If specific predisposing viruses were known, the establishment of a persistent infection could likely be prevented by vaccination of the individuals themselves, of their environment (herd immunity), or specifically of their mothers in case of vertical transmission $(10,13)$. Moreover, healthy virus carriers at risk for viral déjà vu disease could be identified by molecular fingerprint analysis of the persisting virus. Unlike for self antigens, a persisting virus could then be eradicated by drug treatment reverting the predisposition to immune disease.

Third, the viral déjà vu mechanism offers an attractive explanation for the epidemiological observations linking predisposition to immune diseases with environmental factors in early childhood

\section{Figure 8}

Schematic interpretation of the viral déjà vu immunopathogenetic mechanism. (A) Summary of the infection protocol eliciting CNS disease; viral distribution is denoted by color. (B) Mechanistic interpretation. In neonates and in adults, a substantial fraction of the rLCMV/ INDG i.c. inoculum reaches the systemic circulation (38). Viral infection of secondary lymphoid organs is abortive due to efficient type I IFNdependent control, whereas CNS infection is productive. In neonates but not in adults, viral gene expression in secondary lymphoid organs coincides with reduced $T$ cell responsiveness. Hence adult mice mount a protective virus-specific (NP396 and other epitopes) CD8+ $T$ cell response that clears $\mathrm{rLCMV/INDG}$ from the CNS, while virus persists in the neonate's neurons. The antiviral CD8 ${ }^{+} \mathrm{T}$ cell response in neonates is inefficient, but ARM infection 50 days later triggers a vigorous response of NP396-specific CTLs (epitope shared by rLCMV/ INDG and ARM) that causes CNS disease when reaching persistently rLCMV/INDG-infected neurons. Adult primary rLCMV/INDG infection has been cleared from the CNS, and hence only neonatally rLCMV/ INDG-infected mice develop disease.
$(2,8,10,12,13)$. Molecular mimicry may account for the association of some infections with onset of immune disease, and the fertile field hypothesis represents an attractive postulate to explain virally mediated predisposition separate from the onset of disease. Yet the association between young age and a predisposing event is best explained by the viral déjà vu mechanism linking immunological immaturity and viral persistence.

Peripheral tolerance represents a second cornerstone for prevention of self-destructive disease (41), and persisting rLCMV/ INDG may benefit from similar mechanisms of peripheral $\mathrm{T}$ cell tolerance, as self antigens do. Inappropriate antigen presentation in the neonatal period of first $\mathrm{rLCMV} / \mathrm{INDG}$ encounter is likely one of them (42). Later in life, relatively tight containment of rLCMV/INDG in the CNS (see Table 1) suggests clonal ignorance (41) of the inefficiently expanded antiviral $\mathrm{T}$ cell compartment, but additional mechanisms such as regulatory $\mathrm{T}$ cells may also be possible. Déjà vu with ARM, however, seems

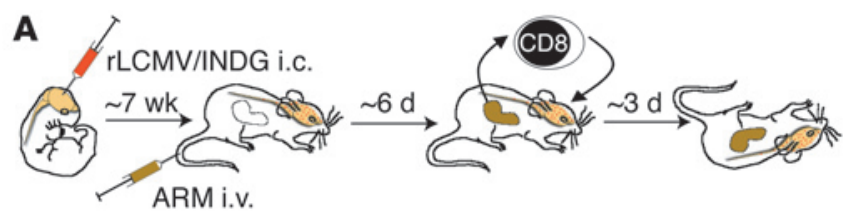

B

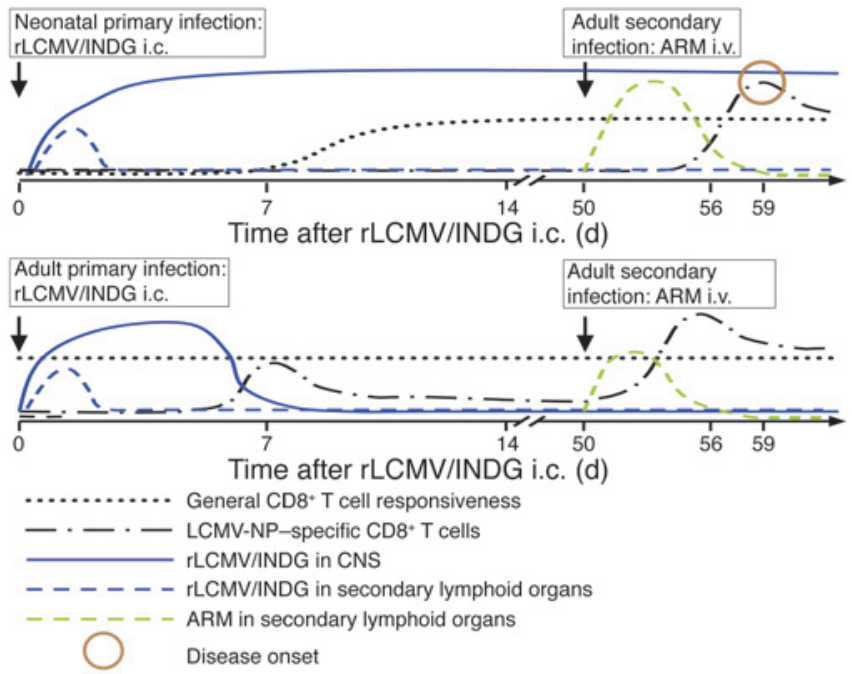


to overrule them, likely by a combination of specific (i.e., TCRdelivered) and nonspecific stimuli of the viral infection (e.g., toll-like receptor signals).

Despite our demonstration that viral déjà vu mimicked organspecific autoimmunity in WT inbred mouse strains, this concept - just like the other postulates (20-23) - awaits formal testing and verification in human autoimmune diseases (25). Importantly, the similarity of viral déjà vu to RE at the histomorphological level does not allow for conclusions regarding the etiology of this disorder. Yet it shows that the morphological appearance leading to the classification of RE as autoimmune disease could just as well result from viral déjà vu operating independently of reactivity to self. Therefore the insights provided by our model may be pivotal for the interpretation of available clinical data on viral infections and autoimmune diseases $(5,6,9,10,12,13)$ and for the future design of clinical studies. Instead of serologic surrogate markers $(5,9,10,13)$, detailed genetic fingerprinting (6) in affected tissues may be needed to link autoimmune disorders to a causative viral variant persisting in an affected organ. Human herpesvirus 6 may serve as an example: Subtype 6B with $>95 \%$ seroprevalence worldwide (potential predisposing virus) persists in oligodendrocytes (43), whereas the rare subtype $6 \mathrm{~A}$ is serologically indistinguishable but frequently found in the serum of MS patients with relapses (6) (potential precipitating virus). Accordingly, measurements of LCMV-NP-specific serum IgG failed to differentiate mice at risk for CNS immune disease (rLCMV/INDG carriers) from $\mathrm{rLCMV} / \mathrm{INDG}$-immune mice that were not at risk (Supplemental Figure 8). Similarly, antiviral serum IgG levels in mice with viral déjà vu disease were similar to those of healthy ARM-immune mice.

Finally, it is important to note that the concepts of molecular mimicry (20), epitope spreading (21), bystander damage (22), fertile field (23), and viral déjà vu are by no means mutually exclusive, and different mechanisms could even lead to clinically indistinguishable syndromes. What renders the viral déjà vu proposal particularly attractive is that it circumvents central $\mathrm{T}$ cell tolerance, that it may disclose new strategies for prevention, and that it can readily explain the epidemiological evidence linking predisposition and precipitation of some organ-specific immune diseases to separate infections in distinct periods of life.

\section{Methods}

Viruses, virus titrations, inoculations, and determination of neutralizing antibodies. Virus stocks were prepared, infectivity was quantified, and VSV neutralizing antibodies were determined as described previously (31). For i.c. inoculations, $3 \times 10^{3} \mathrm{PFU}$ (unless otherwise indicated) of ARM or $\mathrm{rLCMV} / \mathrm{INDG}$ in a volume of $30 \mu \mathrm{l}$ or $30 \mu \mathrm{l}$ of serum were administered through the scull of the vertex using a 27 -gauge needle. For i.v. infection, $2 \times 10^{4} \mathrm{PFU}$ ARM or $2 \times 10^{7} \mathrm{PFU}$ rVSV/LCMV-GP in a volume of $200 \mu \mathrm{l}$ were administered into the tail vein.

Mice. C57BL/6, $R A G^{-/-}, A^{-/-} R A G^{-/-}$(34), and $\mu M T$ mice (31) were used. $R A G^{-/-}$and $\mu M T$ mice were on a C57BL/6 background, whereas $A^{-/-} R A G^{-/-}$ mice were on a mixed C57BL $/ 6 \times 129 \mathrm{SvEv}$ background. To exclude that the differential virus distribution in $R A G^{-/-}$and $A^{-/-} R A G^{-/-}$mice (Figure $2 \mathrm{~A}$ ) was due to differences in the genetic background, $129 \mathrm{SvEv}$ and $A^{-/-}$mice (on a 129SvEv background; ref. 34) were also tested and yielded analogous results as obtained with $R A G^{-/-}$and C57BL/6 mice (Supplemental Figure $3 \mathrm{~A}$ and data not shown). Experiments were approved and authorized by the Kantonales Veterinäramt Zürich (Zurich, Switzerland) in accordance with the Swiss law for animal protection.
Peptide tolerization. Mice were administered $200 \mu \mathrm{g}$ NP396 peptide in incomplete Freund's adjuvant (IFA) i.p. on days 9, 6, and 3 prior to ARM infection as described previously (35). Controls received diluent in IFA.

Human brain tissue. A human brain biopsy of a patient with RE was obtained from the collection of the Department of Neuropathology at the Georg-August-Universität. Its use for scientific purposes was in accordance with the guidelines of the institutional ethics committee. This study was approved by the ethics committee of the University of Goettingen (Goettingen, Germany).

$R N A$ detection. Viral S segment $(\sim 3.4 \mathrm{~kb})$ and NP mRNA $(\sim 1.8 \mathrm{~kb})$ were detected by Northern hybridization as described previously (30).

Rotarod. Mice were placed on a rotating rod (Rotarod 7650; Ugo Basile Biological Research Apparatus) constantly accelerating from 4 to 40 rounds per minute for a maximum of 300 seconds. Endurance time was monitored, and the values obtained in 3 trials per time point were averaged for further analysis.

Brain-extracted lymphocytes, CTL assays, and flow cytometry. Splenic single-cell suspensions and brain-extracted lymphocytes (44) were tested in primary ${ }^{51} \mathrm{Cr}$ release assays as described previously $(31,44)$ or were restimulated for 5 days in vitro with NP396-pulsed $\left(10^{-6} \mathrm{M}\right)$, irradiated splenocytes, in either the presence or the absence of $30 \mathrm{U} / \mathrm{ml}$ rIL-2. EL-4 cells coated with NP396 $\left(10^{-6} \mathrm{M}\right)$ served as targets. Background killing on uncoated target cells was subtracted. Spontaneous release was 10.6-23.3\%. Epitope-specific IFN- $\gamma$-producing and MHC class I tetramer-binding $\mathrm{CD}^{+} \mathrm{T}$ cells were detected by flow cytometric analysis as described previously (36). Allophycocyanin-conjugated anti-IFN- $\gamma$, FITC-conjugated anti-CD4, PE-conjugated anti-CD8 $\beta$ and anti-CD8 $\alpha$, and peridinin-chlorophyll protein-conjugated anti-B220 were purchased from $B D$ Biosciences - Pharmingen. The frequency of IFN $-\gamma^{+} \mathrm{CD}^{+}$or tetramer ${ }^{+} \mathrm{CD}^{+}$ cells was calculated as a percent of CD8 ${ }^{+} \mathrm{B} 220^{-}$lymphocytes.

Histopathology. Tissues of transcardially perfused mice (4\% paraformaldehyde) were embedded in paraffin. Upon inactivation of endogenous peroxidases (PBS/3\% hydrogen peroxide) and blocking (PBS/10\% FCS), sections were stained with primary antibodies: mouse anti-neuronal nuclei NeuN (Chemicon International), mouse anti-GFAP (astrocytes; Dako), mouse anti-CNPase (oligodendrocytes, myelin; Sternberger Monoclonals), rat anti-human CD3 (cross-reactive with murine T cells; Serotec), mouse anti-human CD8 (Dako), rat anti-MAC3 (microglia/macrophages; BD Biosciences - Pharmingen), rabbit anti-Iba-1 (microglia/macrophages; Wako Pure Chemical Industries Ltd.), FITC-labeled Tomato Lectin (blood vessels; Vector Laboratories), and rabbit anti-LCMVwt serum (referred to as LCMV-NP; ref. 29). Rat anti-mouse CD8 (BD Biosciences - Pharmingen) and goat anti-perforin (Santa Cruz Biotechnology Inc.) were costained on $6-\mu \mathrm{m}$-thick snap-frozen sections. Human brain tissue (paraffin embedded) was stained with mouse anti-human CD8 and mouse anti-human granzyme B (both from Dako). Bound primary antibodies were visualized either by an avidin-biotin technique with 3,3'-diaminobenzidine or alkaline phosphatase/anti-alkaline phosphatase as chromogens (haemalaun counterstaining of nuclei) for light microscopy or with the appropriate speciesspecific Cy3- or Cy2-conjugated secondary antibodies (all from Jackson ImmunoResearch Laboratories Inc.) with DAPI (Sigma-Aldrich) nuclei counterstaining for fluorescence microscopy. For granzyme B-CD8 colocalization, the anti-CD8 antibody was blocked with goat anti-mouse Fab fragments (Jackson ImmunoResearch Laboratories Inc.) after visualizing by Cy3-conjugated secondary antibody. Thereafter, sections were incubated with anti-granzyme B followed by Cy2-conjugated secondary antibody.

Quantification of inflammatory infiltrates. For each animal an area of $\geq 1.5 \times$ $10^{7} \mu \mathrm{m}^{2}$ in brain was analyzed at $\times 200$ magnification to assess the average number of $\mathrm{CD}^{+}$cells $/ \mathrm{mm}^{2}$. The inflammatory index was indicated as a percentage determined by dividing the number of visual fields with $>10$ $\mathrm{CD}^{+} \mathrm{T}$ cells by the total number of visual fields examined. 
Statistics. Analyses were performed with SPSS software (version 11.0) and with GraphPad Prism software (version 4.0). To assess significant differences between single measurements of 2 groups, 2-tailed Student's $t$ tests were used (Figure 5B, Figure 6A, and Figure 7C), whereas differences between single measurements of more than 2 groups were assessed by 1-way ANOVA followed by multiple $t$ tests with Bonferroni adjustment for multiple comparisons if the F test of ANOVA indicated statistically significant differences (Figure 1A, Figure 4C, and Supplemental Figure 8). Two-way ANOVA was performed to test for differences between multiple measurements of 2 or more groups, again followed by multiple $t$ tests with Bonferroni adjustment for multiple comparisons if the $\mathrm{F}$ test of ANOVA indicated statistically significant differences (Figure 1B, Figure 1D, Figure 5A, and overall kinetics of epitope-specific CD8 ${ }^{+}$ $\mathrm{T}$ cells in Figure 1C). For comparisons to reference values or to values of a control group, Dunnett's $t$ tests were performed (Figure 3, A and B; Figure 6, B and C; Figure 7, A and B; Supplemental Figure 7, B and C; and analysis of individual time points in Figure 1C). Reduction in motor performance and loss of body weight were tested in comparison to the highest value prior to disease onset. A $P$ value less than 0.05 was considered significant.

\section{Acknowledgments}

We are indebted to P. Aichele, F. Chisari, W. Fierz, N. Harris, J. Hausmann, H. Hengartner, M. Kerschensteiner, M. Loehning, C. Stadelmann, P. Staeheli, and H. Welzl for helpful discussions and to B. Maruschak and M. Schedensack for expert technical assistance. D. Merkler was supported by the Gemeinnützige Hertie Stiftung. This work was supported by grant 3100A0-104067/1 of the Swiss National Science Foundation (to D.D. Pinschewer) and by the Kanton of Zürich.

Received for publication November 9, 2005, and accepted in revised form February 14, 2006.

Address correspondence to: Daniel D. Pinschewer, Institute of Experimental Immunology, Department of Pathology, University Hospital of Zürich, Schmelzbergstrasse 12, 8091 Zürich, Switzerland. Phone: 41-1-2552989; Fax: 41-1-2554420; E-mail: pinschi@pathol.unizh.ch.
1. Marie, P. 1884. Sclerose en plaque et maladie infecteuses. Prog. Med. 12:287-289.

2. Kurtzke, J.F. 1993. Epidemiologic evidence for multiple sclerosis as an infection. Clin. Microbiol. Rev. 6:382-427.

3. Ebers, G.C., et al. 1986. A population-based study of multiple sclerosis in twins. N. Engl. J. Med. 315:1638-1642.

4. Dyment, D.A., Ebers, G.C., and Sadovnick, A.D. 2004. Genetics of multiple sclerosis. Lancet Neurol. 3:104-110.

5. Sibley, W.A., Bamford, C.R., and Clark, K. 1985. Clinical viral infections and multiple sclerosis. Lancet. 1:1313-1315.

6. Alvarez-Lafuente, R., De las Heras, V., Bartolome, M., Picazo, J.J., and Arroyo, R. 2004. Relapsingremitting multiple sclerosis and human herpesvirus 6 active infection. Arch. Neurol. 61:1523-1527.

7. Kaprio, J., et al. 1992. Concordance for type 1 (insulin-dependent) and type 2 (non-insulin-dependent) diabetes mellitus in a population-based cohort of twins in Finland. Diabetologia. 35:1060-1067.

8. Menser, M.A., Forrest, J.M., and Bransby, R.D. 1978. Rubella infection and diabetes mellitus. Lancet. 1:57-60.

9. Gamble, D.R., Kinsley, M.L., FitzGerald, M.G., Bolton, R., and Taylor, K.W. 1969. Viral antibodies in diabetes mellitus. Br. Med. J. 3:627-630.

10. Hyoty, H., et al. 1995. A prospective study of the role of coxsackie B and other enterovirus infections in the pathogenesis of IDDM. Childhood Diabetes in Finland (DiMe) Study Group. Diabetes. 44:652-657.

11. Yoon, J.W., Austin, M., Onodera, T., and Notkins, A.L. 1979. Isolation of a virus from the pancreas of a child with diabetic ketoacidosis. N. Engl. J. Med. 300:1173-1179.

12. Rothwell, P.M., Staines, A., Smail, P., Wadsworth, E., and McKinney, P. 1996. Seasonality of birth of patients with childhood diabetes in Britain. $B M J$. 312:1456-1457.

13. Dahlquist, G.G., Ivarsson, S., Lindberg, B., and Forsgren, M. 1995. Maternal enteroviral infection during pregnancy as a risk factor for childhood IDDM. A population-based case-control study. Diabetes. 44:408-413.

14. Todd, J.A., Bell, J.I., and McDevitt, H.O. 1987. HLADQ beta gene contributes to susceptibility and resistance to insulin-dependent diabetes mellitus. Nature. 329:599-604.

15. Gamble, D.R., and Taylor, K.W. 1969. Seasonal incidence of diabetes mellitus. Br. Med. J. 3:631-633.

16. Kulmala, P., et al. 1998. Prediction of insulin- dependent diabetes mellitus in siblings of children with diabetes. A population-based study. The Childhood Diabetes in Finland Study Group. J. Clin. Invest. 101:327-336.

17. Rasmussen, T., Olszewski, J., and Lloydsmith, D. 1958. Focal seizures due to chronic localized encephalitis. Neurology. 8:435-445.

18. Bien, C.G., et al. 2002. Destruction of neurons by cytotoxic T cells: a new pathogenic mechanism in Rasmussen's encephalitis. Ann. Neurol. 51:311-318.

19. Hart, Y. 2004. Rasmussen's encephalitis. Epileptic Disord. 6:133-144.

20. Fujinami, R.S., and Oldstone, M.B. 1985. Amino acid homology between the encephalitogenic site of myelin basic protein and virus: mechanism for autoimmunity. Science. 230:1043-1045.

21. Miller, S.D., et al. 1997. Persistent infection with Theiler's virus leads to CNS autoimmunity via epitope spreading. Nat. Med. 3:1133-1136.

22. Horwitz, M.S., et al. 1998. Diabetes induced by Coxsackie virus: initiation by bystander damage and not molecular mimicry. Nat. Med. 4:781-785.

23. von Herrath, M.G., Fujinami, R.S., and Whitton, J.L. 2003. Microorganisms and autoimmunity: making the barren field fertile? Nat. Rev. Microbiol. 1:151-157.

24. Homann, D., et al. 2002. CD40L blockade prevents autoimmune diabetes by induction of bitypic NK/ DC regulatory cells. Immunity. 16:403-415.

25. Benoist, C., and Mathis, D. 2001. Autoimmunity provoked by infection: how good is the case for $\mathrm{T}$ cell epitope mimicry? Nat. Immunol. 2:797-801.

26. Anderson, M.S., et al. 2002. Projection of an immunological self shadow within the thymus by the aire protein. Science. 298:1395-1401.

27. Traub, E. 1936. The epidemiology of lymphocytic choriomeningitis in white mice. J. Exp. Med. 64:183-200.

28. Billingham, R.E., Brent, L., and Medawar, P.B. 1953. "Actively acquired tolerance" of foreign cells. Nature. 172:603-606.

29. Gossmann, J., Lohler, J., and Lehmann-Grube, F. 1991. Entry of antivirally active T lymphocytes into the thymus of virus-infected mice. J. Immunol. 146:293-297.

30. Pinschewer, D.D., Perez, M., Sanchez, A.B., and de la Torre, J.C. 2003. Recombinant lymphocytic choriomeningitis virus expressing vesicular stomatitis virus glycoprotein. Proc. Natl. Acad. Sci. U. S. A. 100:7895-7900.

31. Pinschewer, D.D., et al. 2004. Kinetics of protective antibodies are determined by the viral surface antigen. J. Clin. Invest. 114:988-993. doi:10.1172/ JCI200422374.

32. Cole, G.A., Nathanson, N., and Prendergast, R.A. 1972. Requirement for theta-bearing cells in lymphocytic choriomeningitis virus-induced central nervous system disease. Nature. 238:335-337.

33. Luzuriaga, K., et al. 2000. Early therapy of vertical human immunodeficiency virus type 1 (HIV-1) infection: control of viral replication and absence of persistent HIV-1-specific immune responses. J. Virol. 74:6984-6991.

34. Grob, P., et al. 1999. Role of the individual interferon systems and specific immunity in mice in controlling systemic dissemination of attenuated pseudorabies virus infection. J. Virol. 73:4748-4754.

35. Aichele, P., et al. 1994. Peptide-induced T-cell tolerance to prevent autoimmune diabetes in a transgenic mouse model. Proc. Natl. Acad. Sci. U. S. A. 91:444-448.

36. Probst, H.C., et al. 2003. Immunodominance of an antiviral cytotoxic $\mathrm{T}$ cell response is shaped by the kinetics of viral protein expression. J. Immunol. 171:5415-5422.

37. Oldstone, M.B., Dales, S., Tishon, A., Lewicki, H., and Martin, L. 2005. A role for dual viral hits in causation of subacute sclerosing panencephalitis. J. Exp. Med. 202:1185-1190.

38. Cairns, H.J.F. 1950. Intracerebral inoculation of mice: fate of the inoculum. Nature. 166:910-911.

39. Ohashi, P.S., et al. 1991. Ablation of "tolerance" and induction of diabetes by virus infection in viral antigen transgenic mice. Cell. 65:305-317.

40. Vreugdenhil, G.R., et al. 1998. Molecular mimicry in diabetes mellitus: the homologous domain in coxsackie $\mathrm{B}$ virus protein $2 \mathrm{C}$ and islet autoantigen GAD65 is highly conserved in the coxsackie B-like enteroviruses and binds to the diabetes associated HLA-DR3 molecule. Diabetologia. 41:40-46.

41. Walker, L.S., and Abbas, A.K. 2002. The enemy within: keeping self-reactive $T$ cells at bay in the periphery. Nat. Rev. Immunol. 2:11-19.

42. Ridge, J.P., Fuchs, E.J., and Matzinger, P. 1996. Neonatal tolerance revisited: turning on newborn T cells with dendritic cells. Science. 271:1723-1726. 43. Opsahl, M.L., and Kennedy, P.G. 2005. Early and late HHV-6 gene transcripts in multiple sclerosis lesions and normal appearing white matter. Brain. 128:516-527.

44. Ostler, T., et al. 2001. An improved protocol for measuring cytotoxic $\mathrm{T}$ cell activity in anatomic compartments with low cell numbers. J. Immunol. Methods. 257:155-161. 